\title{
POR QUE HUME NÃO É EMOTIVISTA? ${ }^{1}$ \\ WHY HUME IS NOT EMOTIVIST?
}

\author{
GIOVANI M. LUNARDI \\ (UFSC - Brasil)
}

\begin{abstract}
RESUMO
Na tradição filosófica contemporânea principalmente no âmbito da filosofia analítica, a filosofia moral de David Hume é considerada como legítima representante e precursora da Escola Emotivista. Para essa escola, Hume apresentou de forma definitiva com os argumentos da dicotomia ser/dever-ser (is/ought), suas críticas à metafísica e ao racionalismo, os campos e limites da moralidade. Assim, os emotivistas consideram que questões morais não podem ser derivadas de fatos ou, mais radicalmente, não teriam nenhuma base de racionalidade, sendo puramente manifestação das emoções e paixões. Nesse trabalho, apresentamos dificuldades para a interpretação emotivista e sustentamos que o princípio da simpatia (sympathy) e a teoria do espectador judicioso (judicious spectator) presentes na filosofia moral humeana oferecem suporte para uma interpretação alternativa.

Palavras - chave: Filosofia Moral - David Hume - Emotivismo - Sensibilidade
\end{abstract}

\begin{abstract}
In contemporary philosophical tradition especially in the context of analytic philosophy, moral philosophy of David Hume is regarded as legitimate representative and precursor of the Emotivist School. For this school, Hume showed definitively with the arguments of the dichotomy is/ought to, his criticism of metaphysics and rationalism, the fields and limits of morality. So emotivists consider moral issues can not be derived from facts or, more radically, would have no rational basis, being purely expressions of emotions and passions. In this paper, we present difficulties for the interpretation emotivist and argued that the principle of sympathy and the theory of the judicious spectator in the Humean moral philosophy to support an alternative interpretation.
\end{abstract}

Keywords: Moral Philosophy - David Hume - Emotivism - Sensibility

A filosofia moral de Hume é considerada, principalmente por filósofos analíticos ${ }^{2}$, como fundamento para o argumento de que questões morais não podem ser derivadas de fatos, ou mais radicalmente, não teriam nenhuma base de racionalidade, sendo caracterizadas como puramente manifestações de emoções e paixões. Para os analíticos, o sistema teórico humeano desvelou o abismo intransponível entre questões de fato e questões de valor (is/ought). Ao mesmo tempo, os emotivistas acreditam que a investigação do filósofo escocês não comportaria uma ética substantiva, sendo no máximo uma investigação metaética do fenômeno moral ${ }^{3}$.

Na história da Filosofia, Hume é tratado como legítimo representante do empirismo clássico, discípulo de Locke e Berkeley. Mas, de forma original, seu pensamento foi contra a corrente filosófica da época que saudava o surgimento da ciência física; sendo assim, também, um crítico do empirismo do seu tempo. Hume negou que a ciência física fosse conhecimento certo e comprovado 
a respeito do mundo, uma vez que ela não estaria estabelecida sobre bases racionalmente válidas ${ }^{4}$. Estas dúvidas colocaram "na parede” o próprio empirismo clássico: que juízos universais podem ser garantidos a partir de minhas sensações?

Segundo Ayer, "ao mostrar, por um lado, como uma confiança acrítica na razão havia terminado em dogmatismo, e por outro lado, ao reduzir o mero empirismo ao absurdo, Hume preparara o terreno para Kant" posteriormente, também serviram para que os empiristas lógicos, já no âmbito da filosofia analítica, reformulassem o próprio empirismo clássico. Nesta reformulação, procuraram mostrar que Kant estava errado (os juízos a priori não são sintéticos, mas analíticos) e que o conhecimento é feito de experiência e de relações lógicas.

Ou seja, analíticos e emotivistas, em geral, vêem a filosofia de Hume, como uma antecipação, em muitos de seus aspectos, das suas críticas à metafísica tradicional ${ }^{7}$. De acordo com o filósofo escocês, a metafísica reveste-se de caráter ilusório, enquanto tenta penetrar assuntos inacessíveis ao entendimento humanos: ir além dos fenômenos, descobrir a estrutura da realidade ou natureza das coisas e desvelar relações causais entre objetos ou eventos.

Desta forma, Hume com seu ceticismo, ao combater fortemente as bases racionalistas, metafísicas e dogmáticas da natureza do conhecimento, estabeleceu também, para os lógicos e analíticos a esfera de atuação e os limites da moralidade. É a partir dessa delimitação que os analíticos irão denominar de emotivista para a filosofia moral humeana.

\section{II}

No campo da moral, seguindo os passos principalmente de Hume, a filosofia analítica em sua vertente empirista vai desenvolver a partir dos pensadores do Círculo de Viena, da Escola de Cambridge e da Escola de Oxford, uma área específica de estudos que será a metaética. Devemos ao filósofo de Cambridge G. E. Moore, que foi um dos precursores da filosofia analítica, o desenvolvimento da metaética enquanto campo de estudo da atividade filosófica. A metaética terá por objetivos o estudo da lógica e da linguagem dos conceitos, proposições e argumentações éticas. Assim, numa investigação metaética, não se diz o que se deve ou não fazer, mas se analisa o que se faz ao falar do que se deve fazer ${ }^{8}$. Neste aspecto, irão se desenvolver várias escolas, dentre as quais a escola emotivista, que apresentarão suas análises metaéticas.

Quais são, então, as características da escola emotivista? Podemos explicitar a Escola Emotivista a partir da taxonomia das teorias metaéticas elaborada pelo filósofo de Oxford, Richard Hare9. Influenciado por Moore e Hume, ele é quem vai elaborar uma taxonomia que exprime de 
uma forma ampla e clara as várias escolas metaéticas da filosofia analítica ${ }^{10}$. Hare apropria-se da crítica de Moore ao Naturalismo Moral e a aproxima da idéia de Hume de que a moralidade não diz respeito a "questões de fato". Hare, inclusive é quem vai cunhar a expressão "Lei de Hume" à tese de que é impossível deduzir-se um dever-ser a partir daquilo que é ${ }^{11}$. Segundo Hare, os emotivistas realizam uma interpretação de Hume, sustentando uma clivagem radical entre fatos e valores. Os juízos morais não podem ser justificados na medida em que não existe nenhum procedimento que nos permitisse verificar empiricamente como se verificam os juízos de fato.

Para apresentar o primado das emoções sobre a razão nas questões morais, os emotivistas utilizam as seguintes afirmações de Hume descritas no Tratado (Treatise):

Uma vez que a razão sozinha não pode produzir nenhuma ação nem gerar uma volição, infiro que essa mesma faculdade é igualmente incapaz de impedir uma volição ou de disputar nossa preferência com qualquer paixão ou emoção. (..) A razão é, e deve ser, apenas a escrava das paixões, e não pode aspirar a outra função além de servir e obedecer a elas ${ }^{12}$.

E mais a frente, também no Tratado, escreve Hume: "Nosso senso do dever segue sempre o curso usual e natural de nossas paixões"13. Com tais argumentações, a Escola Emotivista, conforme a taxonomia de Richard Hare, considera Hume como um dos seus representantes, que legitimaria seus princípios básicos:

- as questões morais não podem ser derivadas de "questões de fatos";

- as questões morais não têm nenhuma base de racionalidade;

- as questões morais são caracterizadas como puramente manifestações das emoções, paixões.

Para o emotivismo, na taxonomia de Hare, os juízos morais não são governados pela lógica e não possuem condições de verdade. Os emotivistas sustentam que nos juízos morais não se afirma ou não se diz nada sobre fatos, propriedades ou qualidades objetivas, mas se expressa uma atitude emocional subjetiva ou se procura inculcar em outros uma atitude emocional que é nossa, ou provocar neles determinado efeito emotivo. Ao se posicionarem contrários às teses de que os juízos morais são equivalentes a enunciados não-morais (naturalismo) e as teses de que são enunciados sui generis sobre fatos morais discerníveis por intuição ou apelação a convicções (intuicionismo), os emotivistas concluem rapidamente que não se pode usar a razão sobre questões morais e que os juízos morais são expressões de atitudes irracionais ou não-morais. Partem de uma premissa, a saber, de que as únicas questões sobre as quais podemos raciocinar são as questões fáticas.

O estabelecimento da oposição ser e o dever-ser, transpõe - se também para uma separação entre enunciados descritivos e normativos. Desta forma, os emotivistas operam uma dicotomia entre 
as verdades científicas e as decisões morais, estabelecendo um dualismo que irá reforçar a idéia da irredutibilidade da ética ao mundo objetivo, isto porque o contraste entre fatos (ou proposições científicas) e valores (ou julgamento éticos) baseia-se na distinção entre as razões que fundam as construções do conhecimento científico e emoções que guiam escolhas morais. Assim, para os emotivistas o juízo moral exprime uma atitude, uma disposição do sujeito. A conduta do indivíduo traduz a expressão emotiva do seu julgamento. As escolhas e decisões morais provêm das motivações involuntárias dos nossos sentimentos. A função do juízo moral consiste em exprimir emoções do locutor e despertar o mesmo sentimento no interlocutor. $\mathrm{O}$ emotivismo sublinha, desta forma, os aspectos expressivos dos juízos morais. Estas versões do emotivismo oferecem uma interpretação dos enunciados morais como expressões de sentimentos do falante, reduzindo-os a meras interjeições, as quais têm, em geral, a função de despertar, nos destinatários, sentimentos ou atitudes e levá-los a realizações de determinadas ações. Para os emotivistas, não existe um princípio capaz de servir de critério de justificação a uma ética normativa. Há, então, um ceticismo axiológico que aponta para um irracionalismo e um relativismo moral.

Um dos mais renomados emotivistas, A. J. Ayer considera que as proposições morais não se referem a fatos, não se podendo comprovar empiricamente e, por conseguinte, não tem sentido falar da sua verdade ou falsidade. Os juízos morais desempenham somente uma função expressiva. Para Ayer, expressões normativas de valor, como juízos morais comuns do tipo "é errado roubar dinheiro", não são, a rigor, proposições: não há nada nelas que possa ser verdadeiro ou falso ${ }^{14}$. Ressaltamos, no entanto, que o objetivo de Ayer ao desenvolver sua análise dos juízos morais fosse simplesmente eliminar a fonte de uma possível objeção contra sua tese empirista radical e não o de propor uma teoria metaética completa.

Outro emotivista que desenvolveu uma teoria metaética própria foi C. Stevenson. É importante a citação introdutória do emotivista Charles L. Stevenson, na sua obra Ethics and Language (1944), delimitando os objetivos de sua obra e do próprio papel do filósofo moral:

Não se deveria esperar que um livro sobre método científico cumprisse o trabalho da própria ciência; e não se deve esperar encontrar aqui quaisquer conclusões sobre qual conduta é certa ou errada. O propósito de um estudo analítico ou metodológico, seja de ciência ou de ética, é sempre indireto. Ele espera mandar os outros para suas tarefas com as mentes mais lúcidas e com hábitos de investigação menos perdulários. Isso obriga a um contínuo escrutínio do que esses outros estão fazendo, ou então a análise de significados e métodos se processará em um vácuo; mas não exige que o analista, como tal, participe da investigação que ele analisa. Em ética, qualquer participação direta desse tipo pode ter seus perigos. Ela pode privar a análise de seu distanciamento e distorcer um estudo relativamente neutro em um pleito por algum código de moral especial. Então, embora questões normativas constituam de longe o ramo mais importante da ética, permeando toda a vida do bom senso e ocupando a maior parte da atenção profissional de legisladores, editorialistas, romancistas didáticos, clérigos e filósofos morais, essas questões, aqui, devem ser deixadas sem resposta ${ }^{15}$. 
A visão de Stevenson é a pretensão de uma investigação "neutra" da ética, apenas com uma descrição, explicação e esclarecimento dos significados dos termos éticos e também a caracterização dos métodos gerais pelos quais juízos éticos podem ser provados e defendidos, abrindo mão de qualquer discussão a respeito dos aspectos normativos desses juízos. Stevenson interpreta o aspecto emotivo de modo psicológico. Ele restringe a discussão racional à esfera descritiva e a análise de fatos. Na sua análise, ele insiste, mais do que simplesmente na função expressiva dos juízos morais. Stevenson ressalta a sua função efetiva ou invocadora, dado que, segundo ele, os juízos morais tendem, sobretudo, a evocar certas emoções nos outros sujeitos ou a produzir certo efeito emocional. Em Ethics and language, sua obra principal, Stevenson declara que Hume é o filósofo tradicional que com maior claridade coloca as perguntas que o preocupavam na sua obra e o que levanta as conclusões mais parecidas com as quais está disposto a aceitar ${ }^{16}$.

Assim, tanto Ayer quanto Stevenson coincidem na negação de que os juízos morais desempenham uma função cognoscitiva e que, em virtude do seu significado emotivo, possam ser justificados ou fundamentados racionalmente. Ayer e Stevenson apelam para o que consideram uma idéia básica de Hume: a de que considerações morais não dizem respeito à "questões de fato". Com isto juízos morais, embora possuam algum elemento descritivo, devem ser fundamentalmente expressões de atitudes, de interesses, tendo em vista sua função dinâmica e específica. Nessa linha de interpretação, a natureza da moralidade na filosofia humeana é reduzida à formulação de que a moralidade não está fundamentada na razão, sendo conseqüência, unicamente, da nossa sensibilidade. Assim, a moralidade estaria no âmbito de um puro sentimentalismo que, de um ponto de vista normativo, estaria sujeito a um ceticismo ou relativismo moral.

Vamos apresentar, na continuação, as dificuldades e problemas desta interpretação emotivista da filosofia moral de Hume e examinar aspectos que iluminam possibilidades mais amplas de sua filosofia moral.

\section{III}

Para MacIntyre, existe na teoria moral de Hume elementos emotivistas. No entanto, sua teoria é mais vasta e complexa do que a teoria moral emotivista ${ }^{17}$. Ainda de acordo com MacIntyre, o emotivismo é a teoria moral predominante na filosofia contemporânea e representa toda uma noção atual empobrecida da Ética. Oriundo dos estudos de Moore e do desenvolvimento das técnicas descritivas da filosofia analítica, o emotivismo pretende explicar todos os juízos de valor, sejam quais forem. Tal pretensão, segundo MacIntyre, está fadada ao fracasso. Ao guiar-se por critérios objetivos impessoais, os emotivistas aplicam um tratamento anti-histórico, abstraindo todo conteúdo social, cultural, teleológico e valorativo da filosofia moral. Eles afirmam que não existe e não pode existir justificativa racional válida para qualquer afirmação da existência de padrões morais objetivos 
e impessoais e, portanto, que tais padrões não existem ${ }^{18}$.

Da mesma forma que MacIntyre, a seguir, iremos nos posicionar contrariamente à interpretação emotivista da filosofia humeana. Sabemos, como já alertava John Rawls, que "assim como ocorre com outros escritores fundamentais da filosofia, a interpretação de Hume não tem sido fácil, e em épocas diferentes foi lido de maneiras muito diversas"19. Podemos, em alguns momentos, até fazer "algumas breves concessões aos gostos filosóficos correntes" ${ }^{20}$ no âmbito das teorias da motivação moral, da psicologia da ação ou das teorias da razão prática, mas não como interpretações adequadas da filosofia moral de Hume. Entendemos que a teoria emotivista, bem como suas variações e outras interpretações contemporâneas, são todas reconstruções teóricas sofisticadas e originais que, em alguns casos, estão relacionadas com o pensamento humeano ${ }^{21}$; no entanto, de certa forma, trabalham com categorias anacrônicas ${ }^{22}$ com relação à filosofia de Hume ${ }^{23}$.

Consideramos plausível a interpretação da filosofia moral de Hume que leve em conta dois princípios fundamentais de sua teoria sobre a dinâmica dos sentimentos nos julgamentos morais:

(IV) o princípio da simpatia;

(V) a teoria do espectador judicioso.

\section{IV}

A hipótese de trabalho que vamos perseguir na presente seção é que a visão humeana de uma mente dinâmica desvela a ação dos sentimentos sobre o caráter humano; e, enquanto criaturas essencialmente sociais produzimos para nós próprios uma concepção de um ideal de caráter a ser alcançado. De acordo com Hume, os sentimentos morais surgem de princípios públicos, sociais e universais (cf. E 275).

Para o filósofo escocês,

aprovar um caráter é sentir [to feel] um contentamento original diante dele. Desaprová-lo é sentir um desprazer. A dor e o desprazer, portanto, sendo as causas originais do vício e da virtude, devem ser também as causas de todos os seus efeitos (...). A mera consideração de um caráter generoso e nobre nos proporciona uma satisfação (...). Em contrapartida, a crueldade e a traição nos desagradam por sua própria natureza; é impossível aceitar essas qualidades, estejam elas em nós mesmos ou em outros (T 296-297). (acréscimos nossos)

Iniciamos com a afirmação do filósofo escocês: "na natureza humana (...) a mutabilidade lhe é essencial" $(T 283)^{24}$. Ele continua que, 
(...) temos de admitir que a natureza conferiu aos órgãos da mente humana uma certa disposição própria para produzir uma impressão ou emoção peculiar, que chamamos de orgulho; a essa emoção, atribuiu uma certa idéia, a idéia de $e u$, que se produz infalivelmente. (...) É evidente que jamais possuiríamos tal paixão se não houvesse uma disposição da mente apropriada para ela; e é igualmente evidente que a paixão sempre dirige nosso olhar para nós mesmos, fazendo-nos pensar em nossas próprias qualidades e particularidades. (T287)

De certa forma, o eu é para nós a impressão mais forte e vívida dada pelas paixões. No entanto, a própria experiência das paixões mostra-nos que há momentos em que um outro pode assumir essa condição. Ao reconhecermos no que nos é estranho e novo um semelhante, estabelecese com ele uma comunicação. Como ocorre essa comunicação? É o que examinamos, denominado por Hume, de simpatia: o princípio de "sentir junto".

A simpatia é discutida na seção XI da parte I do Livro II do Tratado (T316-324) e resumida posteriormente em sua seção $T$ 3.3.1 $(T 575)^{25}$. O exame da simpatia permite mostrar com quanta seriedade Hume procurava basear a estrutura de sua teoria da moral em uma ciência da natureza humana. A simpatia, como vamos apresentar, é um sentimento tão importante para o fato natural da moralidade que não poderia deixar de estar fundamentado na sua teoria das paixões.

Na seção XI do Tratado - Do amor à boa reputação -, o filósofo escocês escreve que "não há na natureza humana qualidade mais notável, tanto em si mesma como por suas conseqüências, que nossa propensão a simpatizar com os outros e a receber por comunicação suas inclinações e sentimentos, por mais diferentes ou até contrários aos nossos" (T 316). Segundo Hume,

é a esse princípio que devemos atribuir a grande uniformidade observável no temperamento e no modo de pensar das pessoas de uma mesma nação; é muito mais provável que essa semelhança resulte da simpatia que de uma influência do solo ou do clima, os quais, mesmo que continuem invariavelmente iguais, são incapazes de manter o caráter de uma nação igual por todo um século ( $T 316)$.

O princípio da simpatia explica porque temos cuidado com que os outros pensam sobre nós, denominado por Hume de "amor à boa reputação" [love of fame] (T 316). Todas as paixões relacionadas com o outro "eu sinto mais por comunicação" [I feel more from communication], escreve o filósofo escocês (T317). Isto é óbvio, pois "a natureza preservou uma grande semelhança entre todas as criaturas humanas, e qualquer paixão ou princípio que observemos nas outras pessoas podem encontrar, em algum grau, um paralelo em nós mesmos" (T 318).

O exame do princípio da simpatia permite a Hume confirmar suas teses a respeito do entendimento e das paixões. Ele afirma que,

De fato, é evidente que, quando simpatizamos com as paixões e sentimentos alheios, 
de início esses movimentos aparecem em nossa mente como meras idéias, e nós os concebemos como pertencendo a uma outra pessoa, assim como concebemos qualquer outro fato. Também é evidente que as idéias dos afetos alheios se convertem nas próprias impressões que elas representam, e que as paixões nascem em conformidade com as imagens que delas formamos. Tudo isso é objeto da mais clara experiência e não depende de nenhuma hipótese de filosofia. (...) Porque, para além da relação de causa e efeito, que nos convence da realidade da paixão com que simpatizamos, precisamos das relações de semelhança e contigüidade para sentir a simpatia em sua plenitude. (...) Na simpatia, existe uma conversão evidente de uma idéia em uma impressão. Essa conversão resulta da relação dos objetos conosco. Nosso eu está sempre intimamente presente a nós ( $T 319$ 320). (itálicos acrescentados)

As mesmas relações produzidas pelo entendimento [fabric of the mind] (T 318) - causalidade, semelhança, contiguidade - valem também para as paixões; e "todas essas relações, quando unidas, levam a impressão ou consciência de nossa própria pessoa à idéia dos sentimentos ou paixões das outras pessoas, fazendo que os concebamos da maneira mais forte e vívida" (T318). O princípio da simpatia "corresponde exatamente às operações de nosso entendimento" ( $T$ 320). Da mesma forma que no entendimento, a formação desses sentimentos através do mecanismo humeano da simpatia ocorre no âmbito da imaginação, governados pelos princípios da associação por semelhança, contiguidade e casualidade ${ }^{26}$. Temos a transição das ideias entre objetos semelhantes, de modo tal que, sendo o outro ser humano semelhante a mim, a ideia do outro e a ideia que tenho de mim mesmo tendem a aproximar-se, e mesmo a confundir-se, em minha imaginação, sempre que as circunstâncias a tal se prestem. O princípio da simpatia ou da comunicação é, segundo Hume, "a conversão de uma idéia em uma impressão pela força da imaginação" ( $T$ 427).

A simpatia exerce também sua influência sobre o orgulho e a humildade, pois "podemos observar que, sempre que uma pessoa é elogiada por possuir uma determinada qualidade, tal qualidade, se real, produz por si mesma um orgulho nessa pessoa. Os elogios giram em torno de seu poder, riqueza, família ou virtude; e tudo isso é motivo de vaidade (...)" (T320). O filósofo escocês entende "por orgulho aquela impressão agradável que surge na mente quando a visão de nossa virtude, beleza, riqueza ou poder nos faz ficar satisfeitos com nós mesmos; e que, com humildade, refiro-me à impressão oposta" (T 297).

Também o amor é ele próprio um sentimento prazeroso, e sua presença causa-nos orgulho. O ódio, por sua vez, é um sentimento desagradável e sua presença causa-nos humilhação. Não nascemos completamente egoístas nem completamente altruístas, pois segundo Hume, os sentimentos "não nascem somente daquelas qualidades da mente que, segundo os sistemas vulgares de ética, consideram-se como partes do dever moral, mas também de qualquer outra que tenha uma conexão com o prazer e o desprazer" $(T 297)^{27}$.

Sob essa mesma perspectiva, devido à simpatia, "nada mais natural que abraçarmos neste ponto as opiniões dos outros" ( $T$ 320). A internalização da simpatia de outras pessoas com os 
sentimentos de elogio e censura, amor e ódio têm o efeito de produzir em nós próprios tais sentimentos e, dessa forma, atribuímos a nós os méritos que os outros nos atribuem. A simpatia nos premia com uma sensação boa quando realizamos um ato virtuoso e nos dá uma sensação de desconforto se somos responsáveis por um ato odioso. Escreve Hume que "a tendência a produzir prazer e dor é comum a todas as causas do orgulho ou da humildade, mas também que essa é a única coisa comum a elas; e, conseqüentemente, é a qualidade pela qual operam” ( $T$ 325).

Hume afirma que esses sentimentos de "orgulho e humildade não são paixões meramente humanas, estendendo-se, antes, por todo reino animal" (T 326). Consoante com seu naturalismo, o filósofo escocês escreve que "existe evidentemente a mesma relação de idéias, e derivada das mesmas causas, nas mentes dos animais e dos homens" (T 327). Sua conclusão é que "todos os princípios internos necessários para produzir em nós o orgulho ou a humildade são comuns a todas as criaturas; e, como as causas que despertam essas paixões são também as mesmas, podemos legitimamente concluir que essas causas operam da mesma maneira em todo o reino animal" (T 327-328). Essa afirmação de Hume é revolucionária no sentido de rebaixar o homem ao nível dos outros animais. Os julgamentos humanos sobre o mundo seriam, na verdade, semelhantes a instintos, e Hume aponta como esses instintos podem ser encontrados, tanto em bestas brutas, como nos camponeses mais ignorantes e simplórios. No entanto, o filósofo escocês esclarece que mesmo sendo o "senso da moralidade" [sense of morals] um "princípio inerente à alma" [principle inherent in the soul], esse senso ganha mais força quando,

ao refletir sobre si próprio, aprova os princípios de que deriva, sem encontrar em seu nascimento e origem nada que não seja grande e bom. Aqueles que reduzem o senso da moralidade a instintos originais da mente humana podem defender a causa da virtude com bastante autoridade; mas carecem da vantagem daqueles que explicam esse senso por uma simpatia extensa com a humanidade. (T 619) (itálicos acrescentados)

Mas esse rebaixamento realizado pelo filósofo escocês produz um efeito salutar: somos criaturas com capacidades de agir baseadas em sentimentos comuns de dor e prazer. Ou seja, há um fundamento natural que desvela nossa base animal. Não existe nenhum processo complexo de raciocínio relacionados com as sensações de dor e prazer. O que acontece é que os animais agem de modo instintivo e mecânico, exatamente como os seres humanos: a forma como entendemos a dinâmica das sensações "pode ser aplicada a todas as criaturas sensíveis" (T328) ${ }^{28}$. Desse argumento humeano, podemos extrair uma posição moral universalista contra toda forma de discriminação "espeicista" ou "antropocêntrica" - somos, homens e animais, todas criaturas com as mesmas capacidades sensíveis.

No entanto, antes que estimulados pelas afirmações acima, tenhamos a tentação de, também, extrair conclusões para teses naturalistas de conteúdo determinista ou darwinista, lembremos 
que, para Hume, nossa natureza humana é um complexo de sentimentos. A natureza humana é essencialmente inventiva, sensível, suscetível às paixões extremas e às criações surpreendentes. Escreve o filósofo escocês:

Aqueles que se comprazem em lançar invectivas contra a natureza humana observaram que o homem é inteiramente incapaz de se bastar a si mesmo, e que, se desfizermos todos os laços que mantém com os objetos externos, ele imediatamente mergulhará na mais profunda melancolia e desespero. (...) Estou de acordo com esse modo de pensar, pois reconheço que a mente é insuficiente para entreter a si mesma, e por isso busca naturalmente objetos estranhos que possam produzir uma sensação vivaz e agitar seus espíritos animais. (...) Por isso a companhia alheia é naturalmente tão prazerosa, por apresentar o mais vívido de todos os objetos: um ser racional e pensante como nós, que nos comunica todas as ações de sua mente, confia-nos seus sentimentos e afetos mais íntimos, e permite que vislumbremos, no momento mesmo em que se produzem, todas as emoções causadas por um objeto ( $T$ 352-353). (itálicos acrescentados)

De acordo com Hume, quando nos referimos aos demais homens, estamos falando de seres racionais e pensantes (cf. T353). Ou seja, amamos ou odiamos aqueles por quem já sentimos alguma correspondência ou proximidade. Por mais que uma pessoa nos seja estranha, ainda podemos perceber que se trata de um ser humano. Não posso saber o que um outro homem pensa ou sente, porém sou capaz de entender que ele pensa e sente. Evidentemente, essa semelhança não exclui as diferenças que existem entre mim e o outro, mas é suficiente para assegurar uma correspondência: existe um vínculo que nos une. Por exemplo, o amor e o ódio dependem dessa relação de reciprocidade entre os homens: em sentido estrito, só sentimos apreço ou desprezo por aqueles que julgamos semelhantes, dotados das mesmas faculdades que nós. Muitas vezes, afirma Hume,

nosso interesse pessoal não entra em consideração (...), deve ser por mera comunicação que ela nos agrada, e por simpatizamos com o proprietário (...). Entramos em seu interesse pela força da imaginação, e sentimos [feel] a mesma satisfação que esses objetos naturalmente nele ocasionam ( $T$ 363).

Em resumo: somos seres racionais e pensantes, os quais mantêm uma relação de reciprocidade. Ninguém odeia uma fruta que porventura caia em sua cabeça. A não ser que relacionemos essa queda a alguém. Escreve o filósofo escocês que "podemos nos sentir humilhados por nossas próprias faltas e loucuras, mas só sentimos raiva ou ódio quando prejudicados por outrem” (T 330).

Se não fossemos capaz de perceber outra ideia senão a do $e u$, seriamos muito infelizes. Afinal, "somos incapazes de formar um desejo sequer que não se refira à sociedade. A completa solidão é, talvez, a maior punição que podemos sofrer" ( $T 363)$. Ele continua, 
só homem; ainda que o sol nasça e se ponha a seu comando, que os rios e mares se movam conforme a sua vontade, e a terra forneça espontaneamente tudo que lhe possa ser útil ou agradável - ainda assim ele será infeliz, enquanto não lhe dermos ao menos uma pessoa com quem possa dividir sua felicidade e de cuja estima e amizade possa usufruir ( $T$ 363).

Por meio da simpatia penetramos nos sentimentos presentes em toda a sociedade.

Escreve o filósofo escocês,

todo prazer enlanguesce quando gozado sem companhia, e toda dor se torna mais cruel e intolerável. Quaisquer que sejam as outras paixões que possam nos mover - orgulho, ambição, avareza, curiosidade, vingança ou luxuria -, a alma ou princípio que anima todas elas é a simpatia; não teriam força alguma, se fizéssemos inteira abstração dos pensamentos e sentimentos alheios ( $T$ 363).

A simpatia por outras criaturas é um princípio natural. Sua força é tal que, embora seja "raro encontrar alguém que ame a alguma outra pessoa mais do que a si mesmo", é igualmente "raro encontrar alguém em quem todas as afeições generosas, tomadas em conjunto, não superem todas as egoístas" ( $T$ 487). Esse instinto natural de simpatia ocupa um papel importante na formação de nossas atitudes morais e políticas. Que o homem é incapaz de viver sem sociedade é uma das teses humeanas mais centrais, conforme ele escreve num dos seus ensaios: "nascido em uma família, o homem é obrigado a manter a sociedade, por necessidade, por inclinação natural e por hábito"29. A vida urbana, dizia Hume, é boa para nós. Somente através da organização e da atividade social os seres humanos conseguiram prosperar. Somos seres cooperativos: "ninguém nunca viu um cachorro fazer uma troca justa e deliberada de um osso por outro com outro cachorro" 30 . O estudo da poesia, a música e a arte, assim como a ciência, nos proporciona desafios mentais e nos faz até mais sociais e gregários. No seu ensaio "Do refinamento das artes”, ele escreve: "quanto mais avançam essas artes, mais sociáveis se tornam os homens; nem é mais possível que, enriquecidos pela ciência e dotados de um repertório de conversação, eles se contentem com a solidão ou em viver com seus colegas cidadãos daquela maneira distante que é peculiar às nações ignorantes e bárbaras"31.

Na parte final do Tratado (T 574-621), Hume vai ratificar as teses centrais de sua filosofia moral apresentadas até esse momento: a determinação da moralidade ocorre através do conteúdo valorativo dos sentimentos de dor e prazer, comunicados pelo princípio da simpatia na comunicação. Ele afirma que "o principal motor ou princípio de ação da mente humana é o prazer e a dor; e quando essas sensações são retiradas de nosso pensamento e sentimentos, ficamos, em grande medida, incapazes de paixão ou ação, de desejo ou volição" ( $T$ 574). De acordo com Hume, conforme já observado, 
e que toda qualidade mental, existente em nós ou nos outros, que nos dê uma satisfação quando a consideramos ou refletimos sobre ela será naturalmente virtuosa, assim como toda coisa dessa natureza que nos provoque um desconforto será viciosa” ( $T$ 574-575).

A dor e o prazer possuem uma capacidade produtiva de sentimentos em nós - orgulho e humildade -; nos outros - amor e ódio; sendo equivalentes no que diz respeito às nossas qualidades mentais: "a virtude equivale ao poder de produzir amor ou orgulho, e o vício, ao poder de produzir humildade ou ódio. (...) podemos declarar que uma qualidade da mente é virtuosa quando causa amor ou orgulho; e viciosa, quando causa ódio ou humildade" ( $T$ 575). O filósofo alerta, contudo, que esses sentimentos (amor ou ódio, orgulho ou humildade) para serem produzidos e determinarem o que é a virtude ou o vício, "tem de depender de princípios mentais duradouros, que se estendem por toda a conduta, formando parte do caráter pessoal" (T 575). Assim, "se uma ação é virtuosa ou viciosa, é apenas enquanto signo de alguma qualidade ou caráter", pois somente essas "são levadas em conta na moral" ( $T$ 575). Segundo Hume, "em nossas investigações acerca da origem da moral, nunca devemos considerar uma ação isolada, mas apenas a qualidade ou caráter dos quais a ação procede. Apenas estes são duradouros o bastante para afetar nossos sentimentos sobre a pessoa" (T 575).

Pois, "um homem não se torna patife, enganador e mentiroso por ter feito uma falsa inferência ${ }^{32}$.

A força da simpatia é possível, pois, "as mentes de todos os homens são similares em seus sentimentos e operações; ninguém pode ser movido por um afeto que não possas ocorrer também nas outras pessoas, seja em que grau for" (T 575-576). É o princípio da simpatia que comunica meus sentimentos com os dos outros: todos os afetos passam prontamente de uma pessoa a outra, produzindo movimentos correspondentes em todas as criaturas humanas. Afirma o filósofo escocês que "nenhuma paixão alheia se revela imediatamente à nossa mente. Somos sensíveis apenas as suas causas ou efeitos. É desses que inferimos a paixão; consequentemente são eles que geram nossa simpatia" ( $T$ 576). Para ele, "o prazer de um estranho, por quem não temos nenhuma amizade, agrada-nos somente por simpatia” ( $T$ 576).

Hume considera que mesmo virtudes artificiais, como a justiça, só são virtudes morais porque, graças à simpatia, "nós estendemos nossa aprovação dessas invenções até os países e as épocas mais distantes, muito além de nosso próprio interesse". Ele afirma que “a justiça só é uma virtude moral porque tem essa tendência para o bem da humanidade; e, na verdade, não é senão uma invenção artificial com esse propósito" ( $T$ 577). Não existe nada de "teleológico" nessa afirmação de Hume referente ao "nosso próprio interesse". Todas essas invenções humanas, "como sempre se fizeram acompanhar de um sentimento muito forte de moralidade devemos admitir que basta refletirmos sobre a tendência de um caráter ou qualidade mental para que [experimentemos] ${ }^{33}$ os 
sentimentos de aprovação e censura" ( $T$ 577). Tais sentimentos são considerados de forma imediata, pois segundo ele,

ora, como o meio para se obter um fim só pode ser agradável quando o fim é agradável; e como o bem da sociedade, quando nosso próprio interesse ou dos nossos amigos não está envolvido, só agrada por simpatia, essa simpatia é a fonte do apreço que temos por todas as virtudes artificiais ( $T$ 577).

Podemos resumir da seguinte forma essa sua hipótese: a discriminação entre o vício e a virtude depende consideravelmente do princípio da simpatia. O princípio da simpatia tem uma natureza tão poderosa e sugestiva que intervém em quase todos os nossos sentimentos e paixões. Para Hume,

toda qualidade da mente que produz prazer por sua mera consideração é denominada virtuosa; e toda qualidade que produz dor é classificada de viciosa. Esse prazer e essa dor podem surgir de quatro fontes diferentes. Extraímos prazer da visão de um caráter que é naturalmente capaz de ser útil aos outros ou a própria pessoa, ou que é agradável aos outros ou a própria pessoa ( $T$ 591).

Hume faz uma alerta: a simpatia é muito variável e pode-se pensar que nossos sentimentos morais têm de admitir as mesmas variações. Simpatizamos mais com as pessoas que estão próximas a nós que com as que estão distantes; simpatizamos mais com nossos conhecidos que com estranhos; mais com nossos conterrâneos que com estrangeiros. Nossa situação, tanto no que se refere às pessoas como às coisas, sofre uma flutuação continua; um homem distante de nós pode, dentro de pouco tempo, se tornar um conhecido íntimo. Em geral, todos os sentimentos de censura ou aprovação são variáveis, de acordo com nossa situação de proximidade ou de distância em relação à pessoa censurada ou elogiada, e de acordo também com a disposição presente da mente (cf. T 581-582).

Mas, responde Hume, "para impedir essas contínuas contradições, e para chegarmos a um julgamento mais estável das coisas, fixamo-nos em algum ponto de vista firme e geral, e, em nossos pensamentos, sempre nos situamos nesse ponto de vista, qualquer que seja nossa situação presente" (T 581-582). A simpatia é um princípio de comunicação dos sentimentos entre os envolvidos em geral; "e seria impossível conseguir conversar com alguém em termos razoáveis, se cada um de nós considerasse os caracteres e as pessoas somente tais como nos aparecem de nosso ponto de vista particular" ( $T$ 581). No entanto, "apesar dessas variações de nossa simpatia, damos a mesma aprovação às mesmas qualidades morais, seja na China, seja na Inglaterra. Essas qualidades parecem igualmente virtuosas e inspiram o mesmo apreço em um espectador judicioso" (T 581). De acordo 
com ele, ocorre uma "calibragem" dos nossos sentimentos. A experiência logo nos ensina esse método de corrigir nossos sentimentos ( $T$ 582). Através da simpatia, transmutamos uma idéia para uma impressão. Podemos sentir o que outros sentem. Ou seja, a apreciação moral não é individual, específica, mas que se vincula a todos os indivíduos. Essa comunicação pode fazer-nos abandonar um ponto de vista que nos é próprio e fazer-nos considerar um caráter em geral ou, dito de outra maneira, fazer-nos apreendê-lo e vivê-lo como sendo útil a outrem ou à própria pessoa, agradável a outrem ou à própria pessoa. Se cada pessoa apenas considerasse o seu prazer e interesse particular seria “impossível que os homens jamais pudessem concordar em seus sentimentos e juízos, a menos que escolhessem algum ponto de vista comum, a partir do qual pudessem examinar seu objeto, e que pudesse fazer esse objeto parecer o mesmo para todos eles" ( $T$ 591).

Essa resposta humeana é o que denominamos de teoria do espectador judicioso: julgamos o caráter e as ações das pessoas, decidimos o que é uma boa pessoa e determinamos quando o louvor e a censura são apropriados a partir de um ponto de vista geral e comum, de um espectador judicioso capaz de fazer abstração dos seus interesses pessoais, dos interesses de sua perspectiva "peculiar" ou particular. Hume afirma que "é somente quando um caráter é considerado em geral, sem referência a nosso interesse particular, que causa essa sensação ou sentimento em virtude do qual o denominamos moralmente bom ou mau" (T 472). A posição do espectador judicioso providencia mecanismos de avaliação moral de uma forma não-subjetivista e não-solipsista ${ }^{34}$.

Ao assumirmos como plausível essa teoria do espectador de Hume, somos forçados a uma mudança de perspectiva na investigação filosófica da normatividade da moralidade: saímos da perspectiva do exame de como o agente deve agir ou deliberar, para a perspectiva do espectador, que influencia e determina o que é um bom caráter ou uma boa pessoa através dos sentimentos de louvor e censura. Ou seja, de uma teoria centrada no agente, que é basicamente a perspectiva dos racionalistas morais (e, também, dos kantianos e neo-kantianos), vamos para uma teoria centrada no espectador ${ }^{35}$.

A teoria centrada no agente toma os conceitos morais para serem usados pelos agentes na deliberação de como eles devem agir. De forma contrária, segundo Hume, a moralidade não é determinada por um componente deliberativo. Uma boa pessoa pode ser definida - da perspectiva do agente - como alguém que delibera e escolhe corretamente. Mas, Hume define uma boa pessoa - da perspectiva do espectador - como alguém que inspira louvor e admiração. Para ele, conforme já citado, "ter o senso de virtude é simplesmente sentir uma satisfação de um determinado tipo pela contemplação de um caráter. O próprio sentimento constitui nosso elogio e admiração" (T 471). Mas, não damos nossa consideração para qualquer caráter. Segundo Hume, "os caracteres que granjeiam nossa aprovação são principalmente aqueles que contribuem para a paz e segurança da comunidade humana, ao passo que os que provocam a condenação são principalmente aqueles que trazem prejuízo e perturbação públicos" (E 102). Levamos em consideração o caráter em geral, não 
somente os interesses pessoais.

Ele afirma que:

Se alguém, por uma fria insensibilidade ou um temperamento estreitamente egoísta, não for afetado pelas imagens da felicidade ou miséria humanas, deverá permanecer igualmente indiferente às imagens do vício e da virtude; assim como se observa, inversamente, que uma ardente preocupação pelos interesses de nossa espécie é sempre acompanhada de uma refinada sensibilidade para todas as distinções morais: uma forte indignação pelas ofensas feitas às pessoas, uma viva satisfação pelo seu bem-estar. A este respeito, embora se possa observar uma grande superioridade de uma pessoa em relação a outra, ninguém é tão completamente indiferente ao interesse de seus semelhantes a ponto de não reconhecer quaisquer distinções de bondade e maldade morais em conseqüência das diferentes tendências de ações e princípios. Como supor, de fato, que um ser dotado de um coração humano, lhe fosse submetido à apreciação um caráter ou sistema de conduta benéfico e outro pernicioso à sua espécie ou comunidade, não viesse a manifestar pelo menos uma moderada preferência pelo primeiro, ou atribuir-lhe algum mérito e considerações, por menores que sejam? Por mais egoísta que suponhamos ser essa pessoa, por mais que sua atenção esteja absorvida em seus próprios interesses, é inevitável que ela deva sentir, nos casos em que seus interesses não estão em jogo, alguma propensão ao bem da humanidade, e fazer dele o objeto de sua escolha sempre que isso não lhe trouxer maiores conseqüências. (...) Levamos com certeza em consideração a felicidade e a desgraça dos outros ao pesar os diversos motivos para uma ação, e inclinamo-nos para a primeira sempre que considerações de caráter privado não nos levam a procurar nossa própria promoção ou vantagem à custa do prejuízo de nossos semelhantes. E se os princípios humanitários são capazes, em muitas ocasiões, de influenciar nossas ações, eles devem ter em todos os momentos alguma autoridade sobre nossos sentimentos, fazendo-nos aprovar em geral o que é útil para a sociedade e censurar o que é perigoso ou nocivo (E 225-226).

Com essa longa citação podemos demonstrar que há, em sua filosofia moral, um exame do conteúdo do sentimento moral, com uma discriminação desses sentimentos, tais como: a filantropia, benevolência e o interesse geral da comunidade. Os sentimentos morais, para Hume, são práticos, com um conteúdo compreensível e abrangente. Assim, “o vício e a virtude de uma qualidade são determinados por nossas próprias sensações, bem como pelas sensações que essa qualidade possa despertar nas outras pessoas" ( $T$ 597).

Hume reconhece que "todos temos uma prodigiosa parcialidade em favor de nós mesmos", e, também, que "ninguém sabe distinguir bem, em si mesmo, o vício da virtude, ninguém tem certeza de que a avaliação que faz de seu próprio mérito é bem fundada" (T 597-598). Para realizarmos as distinções morais e regularmos nossas ações, "é necessário experimentar (sentir) o sentimento [to feel the sentiment]" a partir da perspectiva do espectador (o apreço e a aprovação da humanidade) e um ideal de caráter a ser contemplado (o caráter de um homem honrado)" (cf. T 598-599).

As distinções morais surgem das distinções naturais entre sensações de dor e prazer, através do "intercâmbio desses sentimentos" (simpatia), produzidos quando sentimos essas sensações (eu) pela consideração geral (do espectador) de uma qualidade ou caráter (do outro) e classificamos a 
estes de viciosos ou de virtuosos (Cf. T 608-609). O espectador não é um partícipe da ação moral: é um terceiro, nem agente, nem paciente. De nossas sensações imediatas, com o intercâmbio dos sentimentos produzidos e comunicados, e refletindo de um ponto de vista geral a respeito do caráter dos homens, nos leva a formar um critério geral e inalterável com base no qual possamos aprovar e desaprovar caracteres e maneiras (Cf.T603). Esse esquema da teoria do espectador judicioso ilustra a hipótese central de Hume: "a distinção entre o vício e a virtude, bem como a origem dos direitos e obrigações morais, que por uma constituição primitiva da natureza, certos caracteres e paixões, só de vistos e contemplados, produzem um desprazer, e outros, de maneira semelhante, suscitam um prazer" (T 296). Na Segunda Investigação, ele esclarece que:

Examine-se, por exemplo, o ato condenável da ingratidão (...). Dissequem-se todas essas circunstâncias, e examine-se apenas pela razão em que consiste o demérito ou a culpa; jamais se chegará a qualquer resultado ou conclusão. (...) Podemos inferir que o ato moralmente condenável da ingratidão não consiste em nenhum fato particular e individual, mas decorre de um complexo de circunstâncias que, ao se apresentarem ao espectador, provocam o sentimento de censura, em razão da peculiar estrutura e organização de sua mente [fabric of his mind]. (E 287-288) (itálicos e parênteses acrescentados)

A teoria do espectador de Hume possibilita garantir a objetividade nas avaliações. É claro que construímos um ideal de caráter, mas o que se apresenta como um ideal tem autonomia em relação ao processo. Como exemplo desse processo, Hume apresenta o seu modelo de virtude perfeita chamado Cleanthes. Esse jovem homem possui qualidades: úteis aos outros, úteis a própria pessoa, agradáveis aos outros e agradáveis a própria pessoa (Cf. E 269). Assim, podemos afirmar que a moralidade surge de uma comunicação natural de nossos sentimentos regulados de "um ponto de vista geral", constituindo um ideal de caráter. Esse ideal de caráter é o produto da comunicação de nossos sentimentos morais, da perspectiva de um espectador judicioso, como criaturas essencialmente sociais. É interessante repetir o exemplo utilizado por Hume retirado da peça Júlio César de Shakespeare. Mesmo em pleno século XXI não invejaríamos o caráter que César atribui a Cássio: "ele não ama os espetáculos como tu, Antônio; ele não ouve música; raramente sorri, e sorri de um modo tal como se zombasse de si mesmo e desprezasse seu espírito por ser levado a sorrir de alguma coisa" (E 251).

Mas, como pode um ideal moral obrigar-nos; ou melhor, como um ideal moral pode ser intrinsecamente normativo? A resposta é que o ideal moral é algo que constituímos para nós próprios. A visão de Hume de uma moralidade determinada pelos sentimentos, com um conteúdo valorativo e regulada pela comunicação desses sentimentos, da perspectiva do espectador, mostra que nossos padrões morais são auto-impostos; ou melhor, impomos um ideal de caráter para nós próprios $^{36}$. A capacidade de discriminarmos e avaliarmos nossas ações está vinculada a forma como sentimos, pois "precisamos tomar uma distância de nos mesmos para que nos transmita alguma 
satisfação. Costumamos considerar a nos mesmos tais como aparecemos aos olhos dos outros, e simpatizamos com os sentimentos que eles tem por nós" ( $T$ 615). Os sentimentos possuem uma capacidade produtiva sendo fonte de obrigação moral com esquemas regulativos que exigem a adoção e o cultivo de um ideal de virtude: "regulamos a nós próprios em termos de nosso próprio ideal de caráter" ${ }^{37}$. Alertamos, no entanto, que primeiro os sentimentos agem sobre nós, depois constituímos nosso ideal de caráter. Segundo ele, "nada pode ser mais real, ou nos interessar mais, que nossos próprios sentimentos de prazer e desprazer; e se estes forem favoráveis à virtude e desfavoráveis ao vício, nada mais pode ser preciso para a regulação de nossa conduta e comportamento" (T 469).

Portanto, a sensibilidade moral, para Hume, possui um conteúdo valorativo com mecanismos e princípios que permitem a discriminação e a correção das ações morais. A filosofia moral de Hume não é fundamentada em uma subjetividade solipsista e nem em um puro hedonismo ou emotivismo.

\section{CONSIDERAÇÕES FINAIS}

Procuramos apresentar por que Hume não é um emotivista, contrariando a interpretação de Ayer e Stevenson, bem como a taxonomia proposta por Richard Hare. O sistema humeano tem sido injustamente acusado de ser excessivamento cético privando a moral de qualquer justificação racional.

O "método experimental" aplicado à filosofia, segundo Hume, pretendia defender a primazia dos fatos experimentalmente constados sobre a forma como os seres humanos pensam e são emocionalmente afetados em sua experiência do mundo e no convívio com seus semelhantes. $\mathrm{O}$ que Hume recusa, e que é diferente de um puro emotivismo, é a representação da natureza humana segundo modelos derivados de hipótese conjunturais como, por exemplo, a "racionalidade"; ao mesmo tempo, a conseqüente tentativa de fundamentar exclusivamente na razão todas as atividades que são próprias do ser humano.

Sua obra foi alvo de vários reducionismos, tais como: um mero ceticismo, um puro psicologismo, ou o tema que foi objeto de análise neste trabalho: a negação de toda e qualquer racionalidade na esfera do conhecimento moral.

Hume foi de fato um crítico ao dogmatismo de seu tempo, seja na vertente empirista, racionalista ou metafísica. Ele possui uma teoria naturalista da moral, resguardando um realismo vinculado aos sentimentos humanos. Contrariamente aos emotivistas, há uma sensibilidade e reflexividade na moral humeana que não é abstrata, relativista, hedonista e nem puramente um ceticismo normativo. 


\section{NOTAS}

${ }^{1}$ O presente trabalho faz parte de pesquisas iniciadas em 2001 no SAPE (Seminário de Aprofundamento em Pesquisas Éticas) coordenado pelo Prof. Darlei Dall'Agnol (UFSC). Posteriormente, essas pesquisas deram origem a dissertação de mestrado intitulada A Universalizabilidade dos Juízos Morais na Ética de Hare, defendida no Programa de PósGraduação em Filosofia da UFSC, sob a orientação do Prof. Darlei Dall'Agnol, em 2003; com continuidade no curso de Doutorado em Filosofia do Programa de Pós-Graduação em Filosofia da UFRGS, sob a orientação do Professor André Klaudat, cuja tese Sensibilidade Moral e Normatividade em Hume foi defendida em 2009.

Outra versão desse trabalho foi apresentada na ANPOF 2006.

${ }^{2}$ Estas correntes filosóficas consideravam que as questões morais primeiramente deveriam se submeter a uma análise do significado lógico (formal) de certos termos modais, para depois se discutir as questões substanciais. A filosofia analítica possui várias vertentes, tais como o Círculo de Viena, a Escola de Cambridge, a Escola de Oxford, dentre outras, com enorme importância para a Filosofia Contemporânea. Vamos considerar como representantes da filosofia analítica: os emotivistas, empiristas lógicos, positivistas e prescritivistas (Frege, Carnap, Russell, Ayer, Stevenson, Hare etc.). É obvio que todos estes pensadores possuem contribuições originais e destacadas, sendo primária a intenção de uma uniformização de suas teorias. Nossa intenção, aqui, é mais no intuito de reforçarmos alguns elementos comuns para nossa argumentação.

${ }^{3}$ Em fins do século XIX, T. H. Green (entre os idealistas ingleses) tomou a frente (seguindo os críticos escoceses de Hume do século XVIII, por exemplo, T. Reid) na compreensão de Hume como um cético radical e considerou sua visão como a reductio ad absurdum do empirismo.

Cf. AYER, A. J. HUME. São Paulo, Edições Loyola, 2003, pp. 27-31.

Contemporaneamente destacam-se, também, entre os estudiosos de Hume que defendem uma interpretação cética de sua filosofia: Noxon, Fogelin, Norton e Olaso.

Cf. SMITH, Plínio Junqueira. O Ceticismo de Hume. São Paulo: Loyola, 1995, p. 7.

${ }^{4}$ Cf. SIMON, Samuel. (Org.) Filosofia e conhecimento: das formas platônicas ao naturalismo. Brasília: UNB, 2003, pp. 229 e 230.

${ }^{5}$ AYER, 2003, p. 31

${ }^{6}$ Afirma Kant que as dúvidas radicais humeanas o acordaram de seu "sono dogmático".

Cf. KANT, Emmanuel. Prolegômenos a toda Metafísica Futura. Lisboa: Edições 70, 1988, p. 17.

Allen W. Wood sustenta que, nessa citação, Kant está apenas convidando os seus leitores “a encontrar o próprio caminho para a sua filosofia crítica através da reflexão sobre os desafios céticos de Hume". Wood defende que "nunca houve um sono dogmático", e que Kant, desde seus primeiros escritos, já estava bem "desperto".

Cf. WOOD, Allen W. KANT. Porto Alegre: Artmed, 2008, p. 23.

${ }^{7}$ A conclusão da Investigação sobre o entendimento humano é, nesse sentido, freqüentemente citada. Escreve Hume: "Quando percorremos as bibliotecas, convencidos destes princípios, que devastação não deveremos produzir! Se tomarmos em nossas mãos um volume qualquer, de teologia ou metafísica escolástica, por exemplo, façamos a pergunta: Contém ele qualquer raciocínio abstrato referente a números e quantidades? Não. Contém qualquer raciocínio experimental referente a questões de fato e de existência? Não. Às chamas com ele, então, pois não pode conter senão sofismas e ilusão".

HUME, David. Investigações sobre o entendimento humano e sobre os princípios da moral. (Tradução de José Oscar de Almeida Marques) São Paulo: Editora UNESP, 2004, p. 222.

${ }^{8}$ Cf. MOORE, G. E. Principia Ethica. São Paulo: Ícone, 1998, p. 100.

${ }^{9}$ Hare considera que as teorias metaéticas são teorias semânticas, não ontológicas. Ele argumenta que na Ética,(...) uma disputa ontológica como a suposta disputa entre realistas e anti-realistas, se é que esta é, afinal de contas, uma disputa genuína, se transforma bem rapidamente em uma disputa que não é ontológica mas conceitual, e não há maneira de formular, com clareza, essa suposta disputa sobre se realmente há fatos morais ou propriedades morais in rerum natura sem transformá-la em uma disputa sobre como as palavras morais adquirem seu significado. No seu livro Sorting out Ethics de 1997, Hare detalha as análises das teorias metaéticas. Ele prefere, então, usar uma distinção de teorias metaéticas entre descritivistas e não-descritivistas em vez de cognitivistas e não-cognitivistas. Para um cognitivista, os juízos morais são asserções e, portanto, passíveis de serem consideradas verdadeiras ou falsas. Já para um não-cognitivista, a moral não é suscetível de ser apreendida por qualquer ato de cognição. Hare, como veremos é um não-descritivista, mas não um não-cognitivista, pois reserva à razão um papel importante nas discussões éticas.

HARE, Richard M. Sorting out Ethics. Oxford: Clarendon Press, 1997, pp. 42-62.

Essa obra de Hare possui uma edição brasileira, mas que, infelizmente, sua primeira edição saiu com vários erros de impressão: 
HARE, Richard M. Ética: problemas e propostas. São Paulo: Editora UNESP, 2003, pp. 67-94.

Ver também:

BRINK, 1989.

${ }^{10}$ HARE, 2000.

11 "Em todo sistema de moral que até hoje encontrei, sempre notei que o autor segue durante algum tempo o modo comum de raciocinar, estabelecendo a existência de Deus, ou fazendo observações a respeito dos assuntos humanos, quando, de repente, surpreendo-me ao ver que, em vez das cópulas proposicionais usuais, como é e não é, não encontro uma só proposição que não esteja conectada a outra por um deve ou não deve. Essa mudança e imperceptível, porém da maior importância. Pois, como esse deve ou não deve expressa uma nova relação ou afirmação, esta precisaria ser notada e explicada; ao mesmo tempo, seria preciso que se desse uma razão para algo que parece inteiramente inconcebível, ou seja, como essa nova relação pode ser deduzida de outras inteiramente diferentes. Mas já que os autores não costumam usar essa precaução, tomarei a liberdade de recomendá-la aos leitores; estou persuadido de que essa pequena atenção seria suficiente par subverter todos os sistemas correntes de moralidade, e nos faria ver que a distinção entre vício e virtude não esta fundada meramente nas relações dos objetos, nem é percebido pela razão".

HUME, David. Tratado da Natureza Humana: uma tentativa de introduzir o método experimental de raciocínio nos assuntos morais. (Tradução Débora Danowski) São Paulo: Editora UNESP, 2001, p. 509.

HARE, R. M. Freedom and Reason. Oxford: Clarendon Press, 1963. p. 108.

HARE, R. M. Universalisability.In: Proceedings of the Aristotelian Society, vol. LV, 1955.

SEN, A. "Hume's Law and Hare's Rule". Philosophy, Jan. 1996.

${ }^{12}$ HUME, 2001, p. 450 e 451.

${ }^{13}$ Ibidem, p. 524.

${ }^{14}$ AYER, A J. Language, Truth and Logic. Great Britain: Penguin Books, 1974, p.107.

${ }^{15}$ STEVENSON, Charles L. Ethics and Language. New Haven: Yale University Press, 1944, p. I.

${ }^{16}$ STEVENSON, C. L. Etica y Lenguaje. Barcelona: Paidos, 1984.

${ }^{17}$ Cf. MACINTYRE, Alasdair. Depois da Virtude: um estudo em teoria moral. (1981) Bauru: São Paulo, 2001 , p. 35.

${ }^{18}$ Alasdair MacIntyre realiza um estudo interessante sobre as tentativas ao longo da história da filosofia de oferecer uma justificativa racional para a moralidade. Com sua obra 'Depois da Virtude' (1981) e, posteriormente, na obra 'Justiça de Quem? Qual Racionalidade?' (1988), o autor faz referência ao projeto de Hume, que procura fundamentar a moralidade nas paixões porque seus argumentos excluíram a possibilidade de fundamentá-los na razão. Segue dizendo o autor que Kant, ao contrário, fundamenta a moralidade na razão porque seus argumentos excluíram a possibilidade de fundamentá-los nas paixões. O autor complementa ainda que Kierkegaard fundamenta a moralidade na escolha fundamental sem critérios. Portanto, este exclui tanto a razão quanto as paixões. MacIntyre diz: “(...) o total da soma da crítica de cada postura pelos outros demonstrou ser o fracasso de todas. O projeto de oferecer uma justificativa racional da moralidade fracassara decisivamente". Ou seja, ele se refere ao fracasso do projeto iluminista de fundamentação da moralidade. A conclusão do autor é uma crítica que podemos endereçar contra Hume e Kant, e uma defesa da posição aristotélica, quando ele afirma que: (...) a ciência anti-aristotélica impõe limites rígidos aos poderes da razão. A razão é calculadora; sabe avaliar verdades de fato e relações matemáticas, porém nada mais. No campo da prática, portanto, só sabe falar de meios. Precisa calar no tocante aos fins".

MACINTYRE, 2001, pp. 14-102.

${ }^{19}$ RAWLS, 2005, p.28.

${ }^{20}$ BAIER, 1994, p.194.

${ }^{21}$ Podemos perceber com algum esforço imaginativo o "espírito" de Hume nas reconstruções teóricas sofisticadas e originais presente nas seguintes teorias filosóficas:

1. O "quase-realismo" de S. Blackburn; 2. O "expressivismo de normas" de A. Gibbard; 3. A psicologia dualista "crença-desejo" de M. Smith.

${ }^{22}$ Cf. BAIER, 1994, p. 194.

${ }^{23}$ Cf. COLEMAN, 1992, p. 332.

${ }^{24}$ A mente humana, segundo Hume, é dinâmica e mutável, onde ocorrem mecanismos naturais de associação, como o das percepções: os princípios de associação de ideias. Para uma discussão crítica a respeito do tema das "ideias abstratas" e "associacionismo" em Hume consulte:

KLAUDAT, André. "As idéias abstratas, a particularidade das percepções e a natureza do projeto filosófico em Hume”. MANUSCRITO, Campinas, n. XX (2), p. 95-121, outubro. 1997.

${ }^{25}$ Nas Investigações, Hume não apela de forma explícita ao princípio da simpatia. No entanto, o mesmo faz parte de sua hipótese central que repetimos: "A hipótese que adotamos é clara. Ela afirma que a moralidade é determinada pelo sentimento, e define a virtude como qualquer ação ou qualidade mental que comunica ao espectador um sentimento agradável de aprovação; e o vício como o seu contrário" (E 289) (grifos nossos). Ele também escreve que "eis aqui a 
mais perfeita moralidade que conhecemos, na qual se manifesta a força de muitas simpatias" (E 276).

${ }^{26}$ Um exame para esclarecer e demonstrar a importância do princípio da imaginação na filosofia de Hume nos levaria a outra investigação. Rapidamente, podemos afirmar que em uma leitura sobre a imaginação em Hume, tudo indica que é o local onde os eventos se tornam próximos ou apresentam uma situação de contiguidade entre os objetos e, ao mesmo tempo, onde se processa a relação causal; sendo assim, a imaginação ocupa uma posição de destaque e, ao mesmo tempo, não definida na filosofia humeana. Na imaginação, as crenças e os sentimentos residem ou encontram locação. A imaginação parece ser capaz de unir ou separar diversas idéias e, assim, construir relatos, fábulas ou criaturas para as quais não encontra impressão correspondente. Segundo o filósofo escocês, "nossa imaginação tem grande autoridade sobre suas ideias, e não há nenhuma idéia diversa de outra que ela não pode separar, unir e compor nas mais variadas formas da fantasia" (Sumário, 1975, p. 44). Com bem expressa Deleuze, "na filosofia de Hume, nada se faz pela imaginação, tudo se faz na imaginação".

Cf. DELEUZE, 2001, p. 13.

${ }^{27}$ Além da crítica aos dogmáticos e racionalistas morais, podemos perceber claramente o distanciamento filosófico de Hume de alguns dos seus contemporâneos sentimentalistas:

- Lord Shaftesbury (1671-1713) afirma que o objetivo do ser humano - dotado de um sentimento natural para distinguir o bem do mal, o certo do errado - consiste num fim social. Sendo, portanto, o fim da moral social, as ações humanas são em geral virtuosas, já que o homem é naturalmente altruísta, e visam ao bem comum da sociedade. Ou seja, a tendência natural do homem é realizar a benevolência.

- Contra tal posição investiu Bernard de Mandeville (1670-1733), ao arguir que não há evidência empírica de que o homem é naturalmente altruísta e que os atos virtuosos são benéficos à sociedade. Pelo contrário, ele considera o vício e o egoísmo como estímulos ao desenvolvimento social.

- Francis Hutcheson (1694-1746), influenciado por Shaftesbury, retoma e repensa o tópico do sentido moral. O sentimento moral é o que percebe aquelas propriedades que despertam as respostas do sentimento moral. As propriedades que suscitam uma resposta agradável e de aprovação são as de benevolência. Não aprovamos as ações em si mesmas, mas aquelas ações como manifestações dos traços de caráter, e nossa aprovação parece consistir simplesmente na suscitação da resposta adequada.

- Joseph Butler (1692-1752) foi contra duas das posições mais centrais de Hutcheson. Butler parte de uma posição mais próxima a Shaftesbury e sustenta que temos uma variedade de apetites, paixões e afetos. A benevolência é um mero afeto, entre outros, que deve ocupar a posição que merece, mas nada mais. Segundo Butler, existe um princípio superior de reflexão ou consciência em cada homem, que distingue entre os princípios internos de seu coração, da mesma forma que entre suas ações externas.

${ }^{28}$ A respeito de uma possível aproximação teórica entre a filosofia de Hume e o naturalismo evolucionista ou darwinista consulte:

-MONTEIRO, João Paulo. Novos Estudos Humeanos. São Paulo: Discurso Editorial, 2003.

-MATOS, José Cláudio Morelli. O naturalismo de Hume e a epistemologia evolutiva. 243 p. Tese (Doutorado em Filosofia) Programa de Pós-Graduação em Filosofia, Universidade de São Paulo, São Paulo, 2004.

-RUSE, Michael. "Uma defesa da Ética Evolucionista”. In:CHANGEUX, Jean-Pierre (Org.). Fundamentos Naturais da Ética. Lisboa: Instituto Piaget, 1993.

${ }^{29}$ Citado por:

MONTEIRO, 2003, p. 164.

${ }^{30} \mathrm{Cf}$. EDMONDS \& EIDINOW, 2008, p. 169.

${ }^{31}$ HUME, David. "Do refinamento das artes". In: Ensaios Morais, Políticos e Literários. Rio de Janeiro: TopBooks Editora, 2004, p. 422.

${ }^{32}$ Cf. EDMONDS\&EIDINOW, 2008, p.315.

${ }^{33}$ Expressão não utilizada por Hume, acrescentada pela tradutora.

${ }^{34}$ A posição do espectador judicioso não pode ser confundida com a perspectiva de um espectador que assume uma imparcialidade "neutra", "cega" ou "distante".

${ }^{35}$ BROWN, CHARLOTTE. "From Spectator to Agent: Hume's Theory of Obligation”. HUME STUDIES, Volume XX, Number 1, pp. 19-35, April 1994, pp. 20-21.

${ }^{36}$ Ibidem, p. 28.

${ }^{37}$ Ibidem, p. 31. 


\section{REFERÊNCIAS}

AYER, A J. Hume. Oxford: Oxford U. P., 1980.

AYER, A J. Hume. (Tradução de Luis Paulo Rouanet) São Paulo: Edições Loyola, 2003.

AZEVEDO, Marcos A. O. A "Lei de Hume": Investigação sobre o naturalismo moral. 2002. 400 p. Tese (Doutorado em Filosofia) - Programa de Pós-Graduação em Filosofia, Universidade Federal do Rio Grande do Sul, Porto Alegre, 2002.

BAIER, Annette. Postures of the mind. Minneapolis: University of Minnesota Press, 1985.

BAIER, Annette. Moral prejudices. Cambridge, Mass.: Harward University Press, 1993, p. 147.

BAIER, Annette. A Progress of Sentiments: reflections on Hume's Treatise. Cambridge, Mass.: Harvard U. P., 1994.

BAIER, Annette. "Moral sentiments, and the difference they make". In: The Aristotelian Society. Supplementary Volume LXIX, pp. 15-30, 1995.

BROWN, CHARLOTTE. "From Spectator to Agent: Hume's Theory of Obligation". In: Hume Studies. Vol. XX, N. 1, pp. 19-35, April 1994.

COLEMAN, Dorothy. "Hume’s internalism”. In: Hume Studies, vol. XVIII, n. 2, pp. 331-348, November 1992.

CONTE, Jaimir. "Sobre a natureza da teoria moral de Hume". In: Kriterion. nr. 113, pp. 131-146, Belo Horizonte, Jun $\backslash 2006$.

CULLITY, Garret and GAUT, Berys. Ethics and Practical Reason. Oxford: Clarendon Press, 1997.

DALL'AGNOL, Darlei. Valor intrínseco: metaética, ética normativa e ética prática em G. E. Moore. Florianópolis: Ed. UFSC, 2005.

DELEUZE, Gilles. Empirismo e Subjetividade: Ensaio sobre a natureza humana segundo Hume. (Trad. Luiz B. L. Orlandi) São Paulo: Ed. 34, 2001.

DREIR, James. "Humean Doubts the Practical Justification of Morality". In: CULLITY, Garrett. \& GAUT, Berys (Ed.) Ethics and Practical Reason. Oxford: Claredon Press, 1997.

EDMONDS, David. \& EIDINOW, John. O cachorro de Rousseau: como o afeto de um cão foi que restou da briga entre Rousseau e David Hume. Rio de Janeiro: Nova Fronteira, 2008.

GUIMARAES, Lívia. "Simpatia, moral e conhecimento na filosofia de Hume". In: Dois Pontos. Curitiba, Vol. 4, número 2, pp. 203-221, outubro de 2007.

GUIMARÃES, Lívia. “Hume”. In: PECORARO, Rossano. (Org.) Os filósofos clássicos da Filosofia. (Vol. I) Petrópolis, RJ: Vozes; Rio de Janeiro: PUC-Rio, 2008. HARE, R. M. "Universalisability". Proceedings of the Aristotelian Society, vol. LV, 1955.

HARE, R. M. Freedom and Reason. Oxford: Clarendon Press, 1963.

HARE, R. M. Sorting out Ethics. Oxford: Clarendon Press, 1997, pp. 42-62. 
HARE, R. M. Ética: problemas e propostas. São Paulo: Editora UNESP, 2003.

HAMPTON, Jean. “Does Hume Have an Instrumental Conception of Practical Reason?”. In: Hume Studies. Oxford, USA, Vol. XXI, n. 1, p. 57-74, Abril 1995.

HUBIN, Donald. "The Groundless Normativity of Instrumental Rationality". In: The Journal of Philosophy, New York, Vol. MCVIII, n. 9, p. 445-468, September 2001.

HUBIN, Donald. "What's Special about Humeanism”. In: Nô̂s. Oxford, Vol. XXXIII, n. 1, p. 30-45, March 1999.

KAIL, P.J.E. Projection and Realism in Hume's Philosophy. New York: Oxford University Press, 2007.

KLAUDAT, André. “As idéias abstratas, a particularidade das percepções e a natureza do Projeto Filosófico em Hume”. In: Manuscrito. Campinas, Col. XX, n. 2, p. 95-122, Outubro 1997. ."Hume, Liberty and the object of moral evaluation". In: Kriterion. Belo Horizonte, n. 108, p. 191-208, Dez/2003. . "Hume e a Determinação da Mente". In: GUIMARÃES, Lívia. Ensaios sobre Hume. (II Colóquio Hume). Belo Horizonte: SEGRAC, 2005.

KEMP SMITH, Norman. The Philosophy of David Hume. London: Macmillan, 1941.

KORSGAARD. Christine M. The Sources of Normativity. United Kingdom: Cambridge U. P., 1998.

KORSGAARD. Christine M. "Skepticism about Practical Reason". In: Creating the Kingdom of Ends. Cambridge: Cambridge University Press, 1996.

LUNARDI, Giovani M. Naturalismo Moral e a "Lei de Hume" na Meta-Ética de Richard Hare. Livro de Atas (Resumos). Salvador, BA: ANPOF, 2004, p. 182.

ANPOF, 2006, p. 220.

Por que Hume não é emotivista? Livro de Atas (Resumos). Salvador, BA:

. Natureza e Naturalismo Moral em Hume. Caderno de Resumos. In: V Simpósio Internacional Principia. Florianópolis, SC: NEL/UFSC, 2007, p. 71-72.

$2008, \mathrm{n} / \mathrm{d}$. . A motivação moral em Hume. Livro de Atas (Resumos). Canela, RS: ANPOF,

MACINTYRE, A. "Hume on 'is' and 'ought'”. In: HUDSON, W. D. The is-ought question. London: Macmillan, 1969. pp. 35-50.

MACINTYRE, Alasdair. Depois da virtude: um estudo em teoria moral. Bauru: EDUSC, 2000.

MACINTYRE, Alasdair. Justiça de Quem? Qual racionalidade. (Tradução de Marcelo Pimenta Marques) São Paulo: Edições Loyola, 1991.

MACKIE, J. L. Hume’s Moral Theory. London: Routledge, 1980.

MALHERBE, Michel. Kant ou Hume - La Raison et le Sensible (2 ed.). Paris: Librairie Philosophique J. Vrin, 1980.

MARQUES, José O. de A. "A crítica de Hume ao argumento do Desígnio”. In: GUIMARÃES, 
Lívia. Ensaios sobre Hume. (II Colóquio Hume). Belo Horizonte: SEGRAC, 2005.

MASON, Michelle. "Hume e Humeans on Practical Reason”. In: Hume Studies, vol. 31, n. 2, November 2005, pp. 347-378.

MONTEIRO, João Paulo. "Hume, Induction and Natural Selection". In: McGuill Hume Studies. San Diego: Austin Hill. 1979. . Hume e a Epistemologia. Lisboa: Imprensa Nacional Casa da Moeda. 1984. . "Hume's Conception of Science". In: TWEYMAN, Stanley (Ed.). David Hume: Critical Assestments. London: Routledge. 1995.

. "Associação e Crença Causal em David Hume". In: Manuscrito. \#XXIII, vol. 1, April, pp. 99-120. Campinas: UNICAMP. 2000. . Novos Estudos Humeanos. São Paulo: Discurso Editorial. 2003.

MOORE, James. "Hume and Hutcheson". In: STEWART \& WRIGHT. (Ed.) Hume and Hume's Connexions. Pennsylvania State: University Press, 1995, pp.23-57.

MOUNCE, H. O. Hume’s Naturalism. London: Routledge. 1999.

NAGEL, Thomas. The possibility of altruism. Princeton: Princeton University Press, 1970.

PHILLIPS, David. "Hume on Pratical Reason: Normativity and Psychology in Treatise 2.3.3". In: Hume Studies. Oxford, Vol. 31, n. 2, November 2005, pp. 299-316.

PORTO, Leonardo Sartori. Hume. (Coleção Passo a Passo nr. 69). Rio de Janeiro, RJ: Jorge Zahar Editor, 2006, p. 39.

RADCLIFFE, Elizabeth S. "Kantian Tunes on a Humean Instrument: Why Hume is not Really a Skeptic About Pratical Reasoning”. In: Canadian Journal of Philosophy, Vol. 27, n. 2, p. 247270, June 1997.

RAWLS, John. História da Filosofia Moral. São Paulo: Martins Fontes, 2005.

SEN, Amartya. “Hume’s Law and Hare’s Rule”. In: Philosophy, Jan. 1996. pp. 75-78.

SIMON, Samuel. (Org.) Filosofia e conhecimento: das formas platônicas ao naturalismo. Brasília: UNB, 2003.

SMITH, Michael. “The Humean Theory of Motivation”. In: Mind. Oxford, Vol. XCVI, p. 36-61, January 1987.

SMITH, Michael. The Moral Problem. Oxford: Blackwell, 1994.

SMITH, Plínio Junqueira. O Ceticismo de Hume. São Paulo: Loyola, 1995.

STROUD, Barry. Hume. London and New York: Routledge, 1977.

STEVENSON, Charles L. Ethics and Language. New Haven: Yale University Press, 1944.

STURGEON, Nicholas L. "Moral Skepticism and Moral Naturalism in Hume's Treatise". In: Hume Studies. Vol. XXVII, n. 1 (April, 2001) 3-84.

VELASCO, Marina. “Hume, as paixões e a motivação”. In: Analytica, Rio de Janeiro, vol. 6, n. 
2, p. 33-60, 2001-2002.

VELASCO, Marina. "Motivação Neo-Humeana: por que acreditar nelas?” In: Manuscrito. Campinas, vol. 26, n. 1, p. 135-182, jan.-jun. 2003.

WILLIAMS, B. Moral Luck. Cambridge: Cambridge University Press, 1981.

WOOD, Allen W. KANT. Porto Alegre: Artmed, 2008. 